New Mortality Experience. $\quad \mathrm{H}^{\mathrm{MF}}, \& c .-$ (continued).

\begin{tabular}{|c|c|c|c|c|c|c|c|}
\hline \multirow{2}{*}{ Age. } & \multicolumn{2}{|c|}{ UNADJDSTED. } & \multicolumn{3}{|c|}{ ADJUSTED. } & \multicolumn{2}{|c|}{$\begin{array}{l}\text { ProBabiLITY of DYiNG } \\
\text { IN A YEAL }\end{array}$} \\
\hline & $\begin{array}{l}\text { Number- } \\
\text { living. }\end{array}$ & $\begin{array}{l}\text { Decre- } \\
\text { ment. }\end{array}$ & $\begin{array}{l}\text { Number- } \\
\text { living. }\end{array}$ & $\begin{array}{l}\text { Decre- } \\
\text { ment. }\end{array}$ & Expectation & $\begin{array}{c}\text { Partial } \\
\text { Experience } \\
\text { Adjusted. }\end{array}$ & $\begin{array}{l}\text { Total } \\
\text { Experience } \\
\text { Adjusted. }\end{array}$ \\
\hline 77 & 19687 & 2113 & 19728 & 2257 & $5 \cdot 811$ & - I1 1441 & • 11322 \\
\hline 78 & 17574 & 2302 & 17471 & 2131 & $5 \cdot 497$ & $\cdot 12197$ & $\cdot 12110$ \\
\hline 79 & 15272 & 2017 & 15340 & 2001 & $5 \cdot 191$ & $\cdot 13044$ & $\cdot 12938$ \\
\hline 80 & 13255 & 1776 & 13339 & 1863 & 4.895 & $\cdot 13966$ & $\cdot 13868$ \\
\hline 81 & 11479 & 1762 & 11476 & 1710 & $4 \cdot 609$ & $\cdot 14901$ & $\cdot 14907$ \\
\hline 82 & 9717 & 1432 & 9766 & 1568 & $4 \cdot 328$ & $\cdot 16055$ & $\cdot 16068$ \\
\hline 83 & 8285 & 1536 & 8198 & 1426 & $4 \cdot 060$ & $\cdot 17394$ & $\cdot 17426$ \\
\hline 84 & 6749 & 1214 & 6772 & 1270 & 3.810 & $\cdot 18753$ & $\cdot 18857$ \\
\hline 85 & 5535 & 1211 & 5502 & 1115 & 3574 & $\cdot 20265$ & -20267 \\
\hline 86 & 4324 & 952 & 4387 & 955 & 3355 & $\cdot 21768$ & $\cdot 21732$ \\
\hline 87 & 3372 & 751 & 3432 & 805 & $3 \cdot 150$ & $\cdot 23455$ & $\cdot 23248$ \\
\hline 88 & 2621 & 691 & 2627 & 651 & $2 \cdot 962$ & $\cdot 24781$ & $2458 \mathrm{I}$ \\
\hline 89 & 1930 & 454 & 1976 & 520 & $2 \cdot 773$ & 26316 & $\cdot 25923$ \\
\hline 90 & 1476 & 394 & 1456 & 411 & $2 \cdot 585$ & $\cdot 28228$ & $\cdot 27778$ \\
\hline 91 & 1082 & 309 & 1045 & 319 & $2 \cdot 405$ & $\cdot 30526$ & $\cdot 29708$ \\
\hline 92 & 773 & 304 & 726 & 233 & $2-242$ & $\cdot 32093$ & '31069 \\
\hline 93 & 469 & 235 & 493 & 168 & $2 \cdot 066$ & $\cdot 34077$ & $\cdot 33029$ \\
\hline 94 & 234 & 0 & 325 & 124 & $1 \cdot 875$ & $\cdot 38154$ & $\cdot 35694$ \\
\hline 95 & 234 & 26 & 201 & 79 & $1 \cdot 724$ & $\cdot 38806$ & $\cdot 36441$ \\
\hline 96 & 208 & 130 & 122 & 48 & $1 * 516$ & $\cdot 39837$ & $\cdot 37334$ \\
\hline 97 & 78 & 39 & 74 & 36 & $1 \cdot 207$ & $\cdot 48648$ & $\cdot 46809$ \\
\hline 98 & 39 & 0 & 38 & 26 & .815 & $\cdot 68420$ & $\cdot 65999$ \\
\hline 99 & 0 & 0 & 12 & 12 & $\cdot 500$ & $1 \cdot 00000$ & $1 \cdot 00000$ \\
\hline 100 & 0 & 0 & 0 & 0 & & & \\
\hline
\end{tabular}

\title{
ON HERR LAZARUS'S PAPER ON THE THEORY OF PROBABILITIES.
}

\section{To the Editor of the Journal of the Institute of Actuaries.}

SiR,--In the July number of the Journal you inserted a letter from me, having for its object the elucidation of a passage in Herr Lazarus's paper "On some problems in the Theory of Probabilities." I have since received a very courteous communication from Herr Lazarus in reference to the subject of my letter; and I beg to send you the substance of that communication out of fairness to Herr Lazarns, at the same time feeling confident that it will greatly interest some of your readers.

He says, in explanation of the passage upon which my remarks were based, "The simplest way to find the sum $\Omega_{0}+\Omega_{1}+\Omega_{2}$ would be to extend " one of the equations (28) or (29), so as to include $\Omega_{0}$. I think it is self" evident from (28) that

$$
\text { " } \Omega_{0}+\Omega_{1}=\frac{\int_{0}^{p} x^{m-1}(1-x)^{n} d x}{\int_{0}^{1} x^{m-1}(1-x)^{n} d x}-\frac{\int_{0}^{p} x^{m+z}(1-x)^{n-z-1} d x}{\int_{0}^{1} x^{m+z}(1-x)^{n-z-1} d x}
$$


" and as by (29) $\boldsymbol{\Omega}_{2}=\frac{\int_{0}^{p} x^{m-z-1}(1-x)^{n+z} d x}{\int_{0}^{1} x^{m-z-1}(1-x)^{n+z} d x}-\frac{\int_{0}^{p} x^{m-1}(1-x)^{n} d x}{\int_{0}^{1} x^{m-1}(1-x)^{n} d x}$;

" it follows directly by mere addition that

$$
“ \Omega_{0}+\Omega_{1}+\Omega_{2}=\frac{\int_{0}^{p} x^{m-z-1}(1-x)^{n+z} d x}{\int_{0}^{1} x^{m-z-1}(1-x)^{n+z} d x}-\frac{\int_{0}^{p} x^{m+z}(1-x)^{n-z-1} d x}{\int_{0}^{1} x^{m+z}(1-x)^{n-z-1} d x}
$$

" and from this equation I derive

“ $\Omega_{0}+\Omega_{1}+\Omega_{2}=\frac{1}{\sqrt{\pi}} \int_{0}^{k_{2}} \varepsilon^{-t^{2}} d t+\frac{1}{\sqrt{\pi}} \int_{0}^{k_{3}} \varepsilon^{-t^{2}} d t+\frac{\mathrm{B}_{2}}{\mathrm{~A}_{2} \sqrt{\pi}} \varepsilon^{-k_{2}^{2}}-\frac{\mathrm{B}_{3}}{\mathrm{~A}_{3} \sqrt{\pi}} \varepsilon^{-k_{3}^{2}}$.

With regard to the signs of the first two terms in this expression, Herr Lazarus says, "On page 246, at the bottom, we found the inequalities

$$
\text { " } m<p(\mu+1), \quad m>p(\mu+1)-1 .
$$

"It follows that

$$
\text { “ } \frac{m}{\mu+1}<p, \quad \frac{m+1}{\mu+1}>p ;
$$

" and in consequence thereof,

$$
\begin{aligned}
& \text { " } \frac{m+z}{\mu-1}>p, \text { the }+ \text { sign of the first term is fixed; } \\
& \text { " } \frac{m-z-1}{\mu-1}<p, \text { the }+ \text { sign of the second term is fixed." }
\end{aligned}
$$

There is thus, then, no necessity for the double sign which I prefixed to these terms. At the same time I think it would have been as well had this step in the demonstration been inserted in Herr Lazarus's paper.

Herr Lazarus kindly points out a misprint in my letter. In the expression for $\Omega_{0}+\Omega_{1}+\Omega_{2}$, on page 454 , the factor $\frac{1}{\sqrt{\pi}}$ has been omitted from the first two terms.

$$
\begin{aligned}
& \text { I am, Sir, } \\
& \text { Your obedient servant, }
\end{aligned}
$$

Dec. 1, 1870, WILLIAM SUTTON.

18, Lincoln's Inn Fields. 